Exploring Norm Violations and Norm Management in Collocated Synchronous Communication: Dual-Channel Communication as Hybrid Space with Spillover and Asymmetries

\title{
Nelimarkka, Matti
}

2021-07-01

Nelimarkka , M , Salovaara , A \& Jacucci , G 2021 , ' Exploring Norm Violations and Norm Management in Collocated Synchronous Communication: Dual-Channel Communication as Hybrid Space with Spillover and Asymmetries ' , Proceedings of the ACM on human-computer interaction , vol. 5 , no. GROUP . https://doi.org/10.1145/3463933

http://hdl.handle.net/10138/333829

https://doi.org/10.1145/3463933

unspecified

acceptedVersion

Downloaded from Helda, University of Helsinki institutional repository.

This is an electronic reprint of the original article.

This reprint may differ from the original in pagination and typographic detail.

Please cite the original version. 


\title{
Exploring Norm Violations and Norm Management in Collocated Synchronous Communication
}

\author{
Dual-channel Communication as Hybrid Space with Spillover and Asymmetries
}

\author{
MATTI NELIMARKKA, University of Helsinki, Social Computing Group, Finland and Aalto University, \\ Department of Computer Science, Finland \\ ANTTI SALOVAARA, Aalto University, Department of Design, Finland \\ GIULIO JACUCCI, University of Helsinki, Department of Computer Science, Finland
}

\begin{abstract}
Digital tools for collocated synchronous communication, like backchannels and question management systems, are increasingly used in events and education to support interaction between performer(s) and audience. Discussions in the communication tool are prone to various unexpected interruptions which violate against the communication tools' original purpose, i.e. violating performers' expected norms. We study such norm violations and related performers' coping approaches in two 15-week-long field experiments in two elementary schools. Our results demonstrate how the collocated synchronous tools form dual-channel communication environment where both physical and digital channel are in use at the same time. We show how norm violations 'spill over' from their onset in one channel to continue in the other. However, we observed performers coping approaches were primarily focused in the physical channel. This resulted in an asymmetry of presence and delayed the performers' ability to act on violations. Our findings show that the channels in dual-channel communication are tightly interwoven and must be considered as an integrated communication space instead of two co-occurring but separate channels. We provide a framework to study norm violations and discuss implications of this framework on the design of these systems.
\end{abstract}

CCS Concepts: $\bullet$ Human-centered computing $\rightarrow$ Collaborative and social computing theory, concepts and paradigms; HCI theory, concepts and models; Empirical studies in collaborative and social computing; Collaborative and social computing systems and tools; • Applied computing $\rightarrow$ Law, social and behavioral sciences.

Additional Key Words and Phrases: Presemo; collocated communication; social norms; norm violations; hybrid space; performer; dual-channel; same-time \& same-place

\section{ACM Reference Format:}

Matti Nelimarkka, Antti Salovaara, and Giulio Jacucci. 2021. Exploring Norm Violations and Norm Management in Collocated Synchronous Communication: Dual-channel Communication as Hybrid Space with Spillover and Asymmetries. Proc. ACM Hum.-Comput. Interact. 5, GROUP, Article 221 (July 2021), 24 pages. https: //doi.org/10.1145/3463933

Authors' addresses: Matti Nelimarkka, University of Helsinki, Social Computing Group, Helsinki, Finland , Aalto University, Department of Computer Science, Espoo, Finland, matti.nelimarkka@helsinki.fi, matti.nelimarkka@aalto.fi; Antti Salovaara, Aalto University, Department of Design, Espoo, Finland, antti.salovaara@aalto.fi; Giulio Jacucci, University of Helsinki, Department of Computer Science, Helsinki, Finland, giulio.jacucci@helsinki.fi.

Permission to make digital or hard copies of all or part of this work for personal or classroom use is granted without fee provided that copies are not made or distributed for profit or commercial advantage and that copies bear this notice and the full citation on the first page. Copyrights for components of this work owned by others than the author(s) must be honored. Abstracting with credit is permitted. To copy otherwise, or republish, to post on servers or to redistribute to lists, requires prior specific permission and/or a fee. Request permissions from permissions@acm.org.

(c) 2021 Copyright held by the owner/author(s). Publication rights licensed to ACM.

2573-0142/2021/7-ART221 \$15.00

https://doi.org/10.1145/3463933

Proc. ACM Hum.-Comput. Interact., Vol. 5, No. GROUP, Article 221. Publication date: July 2021. 


\section{INTRODUCTION}

There have extensive research to demonstrate how digital tools can augmented physically collocated events [e.g. 43, 46, 57] and classroom participation [2, 10, 27, 34, 37, 43, 71]. Nowadays, digital tools for collocated communication are supported by several commercial tools, such as Slido, Mentimeter, Poll Everywhere and Screen.io ${ }^{1}$. Scholars have highlighted how such tools are dualchannel, allowing participants interact through both a physical and a digital channel at the same time $[39,46,58]$. Due to this, it has been shown that such tools support participation and engagement [e.g. 29, 30, 57], promote peer learning [43, 71], create opportunities for focused discussions without side-tracking the face-to-face interactions [5, 43] and improves self-expression [17, 29, 45]. However, there are also disadvantages which can limit how extensively such systems are used. For example, co-existence of two channels may compete for attention and participants may find it harder to follow the presentation in the physical channel [43]. Other problems include posting of off-topic content $[5,20,45]$ and mocking of the performer [e.g. 6].

We are particularly interested in cases where the additional communication channel is used against expectations. They could be seen to break the (un)written behavioural rules which are established in events, at least from the organisersâĂŹ perspective. Therefore, the additional communication channel appears to break the norms. They may limit the uptake of such communication tools in events or for education. Scholars have studied extensively how norms impact technology use and what kinds of steps are conducted to maintain norms [among many others 13, 54, 66]. However, they have focused on single-channel communication. Because of this, we do not have a clear conceptual insight how norm violations and norm management take place in a dual-channel communication.

To address this gap, we develop an initial framework to explore norm violations in dual-channel communication environments and examine how these norm violations are managed. To examine these, we have conducted observations and interviews during a field deployment. The studies are conducted in a school environment as norms in there are well-articulated and actively maintained. Teachers aim to create social environments that would support learning [24, 59]. While pupils may interpret norms and even challenge norms $[28,31]$, the long-term relationship between the teacher and the pupils increases the likelihood that all parties understand what the desired school class behaviour is like. In the following, we first review the literature on norms and how computermediated technologies may support collocated interaction. We outline two research questions (RQs) and provide extended background for each of them. We then describe the study setup and give an overview how the collocated synchronous communication tools were used. Following this, we address each RQ and develop the framework to understand norm violations within classroom. Based on the framework, we discuss two intermediate-level design knowledge brokers or strong concepts [32] - norm violation spillovers and presence asymmetries - that help us understand the complexity that the dual-channel setting brings into performer-audience interactions in collocated settings. Finally, we acknowledge limitations and discuss potential extensions of our work.

\section{THEORETICAL BACKGROUND}

To study norms in collocated synchronous communication, we build on literature about norms and norms management as well as work on collocated synchronous communication. Given that our context is in education, we also apply insights from this domain to enrich our analysis. We will first introduce our understanding about collocated synchronous communication in events, followed by detailed review on about norms, their violations and management.

\footnotetext{
${ }^{1}$ https://www.sli.do/, https://www.mentimeter.com/, https://www.polleverywhere.com/, https://screen.io/en/
} 


\subsection{Analysing collocated synchronous communication systems in events}

There is an extensive body of research addressing collocated synchronous communication systems in event contexts [e.g. 43, 46, 57] and learning settings [e.g. 2, 10, 27, 34, 37, 43, 71]. Across these works, different social roles have been used to analytically to examine the roles. Most scholars agree that there is an 'audience' or 'spectators' and 'performers,' who have a more active role in maintaining the overall event [e.g. 46, 56]. The key insight has been that collocated synchronous communication may help some members of the audience to become more active 'spec-actors' (that is, spectators and actors at the same time), and thereby limit performers role as the only content contributor $[20,60]$. The idea of clearly different performer role is also suitable with teaching, which is sometimes analysed as a performance [52] where the teacher has on overall role of maintaining the analysis.

Second analytical division has been to what kinds of interactions are examined in events augmented with collocated synchronous communication systems. Most of the earlier work has often focused significantly on what takes place in the digital communication channel [e.g. 29, 30, 43, 45, 71]. However, much less focus has been put into the physical communication channel or both channels. Scholars who have tackled these have observed that physical presence is used to guide attention $[39,46]$ and focused on differences between interaction across these channels [58]. This work moves forward to diminish the importance of digital channels and shows that actions occur across these communication channels.

\subsection{Norms and human-computer interaction}

Social norms are representations of acceptable group conduct [9, 38, 61]. Violating them leads to sanctions from community members [22]. In human-computer interaction research, norms have been used to understand what kind of interactions emerge through the design characteristics of user interfaces [e.g. 63, 66] or through other users' actions [e.g. 13, 64]. Similarly, the theoretical concept is well-articulated and applied in sociology and social psychology [e.g., 9]. To avoid further confusion about norms, we wish to articulate more explicitly what we mean by norms. Four categories of norms have been defined [38]:

(1) Collective norms are developed by individuals and are implicitly understood in the community.

(2) Perceived norms are individuals' perspectives on the collective norms.

(3) Injunctive norms are what people believe to be the correct behaviour.

(4) Descriptive norms are defined as those activities that are actually punished by the community.

For the present study, descriptive norms are of interest, as they refer to cases where teachers or fellow pupils might raise up as issues in the classroom. As descriptive norms manifest and impact the collective and perceived norms, they also provide insights into these norms more broadly [38]. Descriptive norms form through social interaction: they may be discussed before the need for punished or they may become visible after the community punishment.

Social norms are essential to guide behaviour also in school environments. However, as a social setting school is different from less hierarchical groups - often studied when we examine norms in relation to technology. Teacher has been given the responsibility to maintain to maintain and define the values, and therefore, also the norms of the classroom [12, 18, 41, 70]. However, students do have agency in the process as well: pupils are not 'judgmental dopes' [28, 31] who obediently follow the norms that a teacher communicates to them. Furthermore, norms evolve over time: there are prior discussions, rule settings and history of norm violations and sanctions. These help teachers and students to create a shared understanding about the descriptive norms. However, when analysing norms, we must be mindful about teachers' expected role about maintaining values 
and norms. Educational scholars highlight that teachers do have an invisible hand to shape the social settings [for reviews, 1].

Therefore, when we focus on descriptive norms which we observed by examining what activities are sanctioned during the class. During class time, teachers have the primary responsibility of sanctioning and maintaining norms. Therefore, the descriptive norms we observe bear similarity to teachersâĂŹ injunctive norms: teachers maintain norms for cases where they perceive as violation of the expected behaviour. While in many cases in classroom activities pupils can take part in these activities (i.e., group work, individual work on exercises), the use of collocated synchronous communication systems is performative: teacher is performing and asking students to engage by participating. Therefore, the settings when these technologies are used is not equal: there are power imbalances which impact on who is expected to sanction and monitor behaviour, leading to differences in how descriptive norms are formed.

To further understand norms, we explore the characteristics and occurrences of norm violations in dual-channel communication (Section 2.3, RQ1) and address research on norm creation and their management (Section 2.4, RQ2).

\subsection{Norm violations}

Norm violations are cases where the expectations set in the norms are broken [44]. They have been extensively studied across technology researchers. For example, McLaughlin and Vitak [44] found how norms might be violated in Facebook use, for example, by publishing excessive amounts of status updates or sharing overly emotional content. They suggested that these activities may break with expectations about the norms of public and private interactions. Similarly, Uski and Lampinen [67] observed that automated profile construction in online communities of interest conflicts with their users' need for "profile work" and self-presentation in their social networks.

Various norm violations can manifest in a school context. A typical norm violation is a situation where students do not behave as the teacher expected, and this interrupts the instruction. Several typologies have been developed to classify classroom interruptions [e.g. 3, 25]. We do not intent to stay that all classroom interruptions are norm violations: for example, such interventions could be caused by education technology not working or another teacher's unexpected visit to the classroom. However, the classification helps us to examine potential cases where norms are violated. Based on these classifications, the norm violations emerge from interventions by either a student or the teacher. For example, if students are asked to work on a task that does not require speaking, general chatter and noise may be considered norm violations if the teacher tries to stop it. Similarly, already earlier research has suggested that dual-channel communication can be used to share extensively negative content about the performer [e.g. 6], breaking many expectations about acceptable social situation towards a keynote speaker.

Based on these observations, it is evident that norms are violated in many context-dependent ways. To date, research has focused on norms violated within a single channel. In dual-channel communication, norm violations may be different. Therefore, we must ask (RQ1) how do norm violations occur in dual-channel communication? This said, with this question we do not claim that the norms are not violated in other cases. We acknowledge that the classrooms may have many norm violations taking place when the dual-channel communication was not in use. Rather, to analysis is on the role of dual-channel communication in norm violations, which drives us to explore dual-channel communication and technology more extensively.

\subsection{Norm management}

As we have suggested above, norms do not emerge out of thin air. Rather, norms are maintained (and formed) by explicit articulations from positions of power (such supervisors or teachers) as well

Proc. ACM Hum.-Comput. Interact., Vol. 5, No. GROUP, Article 221. Publication date: July 2021. 
as individuals' previous experiences about violations [26]. When this norm maintenance is done by those in a position of power, we suggest they are doing norm management: using a collection of strategies to establish their injunctive norms as descriptive norms.

As we have suggested above, in school environments, the role of forming and maintaining norms often belongs to teachers. For example, Doerr and Zangor [18] studied teaching practices when graphic calculators were introduced in schools. They observed that teachers defined how the calculators could be used in the classroom and which tasks should be carried out without teachers' help. Similarly, Loh et al. [41] examined how, when using software tools to support the learning process, teachers needed to be capable of adapting learning software to fit classroom norms.

In classroom settings, norm management can be considered as part of classroom management or classroom orchestration in school settings. Both concepts are used in studies on teachers' preparation and administration of classroom activities. For example, Emmer and Stough [24] describe how teachers manage the use of time and set up the classroom environment. Similarly, while the classroom management literature does not discuss management of norms using this term, teachers are engaged in establishing the expected behaviours. In classroom management, preventive (proactive) strategies are often preferred to reactive ones [24]. Overall, the literature is explicit that teachers orchestrate the environment for their aims and thus do "norm management" [e.g. 24]. As a corollary, it is plausible that norm management strategies should also be preventive: the teacher should attempt to establish norms before imposing coercive strategies.

In second research question (RQ2), we therefore explore what norm-management strategies performers employ. The research gap relates to the dual-channel communication situation. Previous work cited above has focused on single-channel environments and has not addressed the approaches available to manage norms in dual-channel communication.

\section{CASE AND APPROACH}

To answer these research questions, we conducted a field experiment [used both in human-computer interaction and learning sciences, e.g. 7, 8, 14, 15, 50] in two school classes that used a collocated synchronous communication system. We will now describe the system and study setup and elaborate on data collection and analysis approach. We will also briefly contextualise how dual-channel communication was actualised in these classrooms.

\subsection{Presemo}

Computer-mediated communication tools for classroom teaching are available in considerable variety and have been developed both in academia and in industry. Many of the systems are based on the idea of leveraging spectators' personal hand-held devices in the interaction, to create more participatory learning situations and thus invite every student to engage in thinking activity [60]. These types of solutions can be used in various social settings to support group work, including

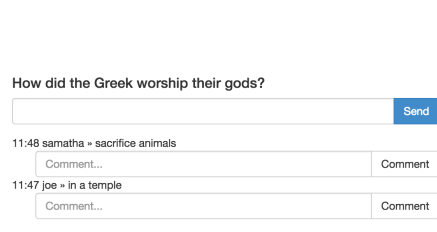

(a) An open-ended chat

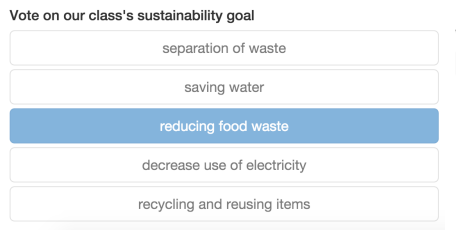

(b) A closed-ended poll

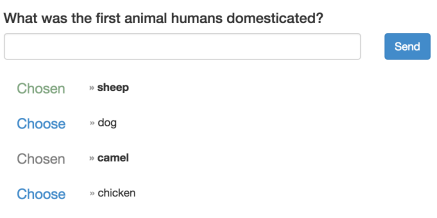

(c) Ranked content

Fig. 1. The pupil's interface to Presemo: three different blocks as seen by a pupil 


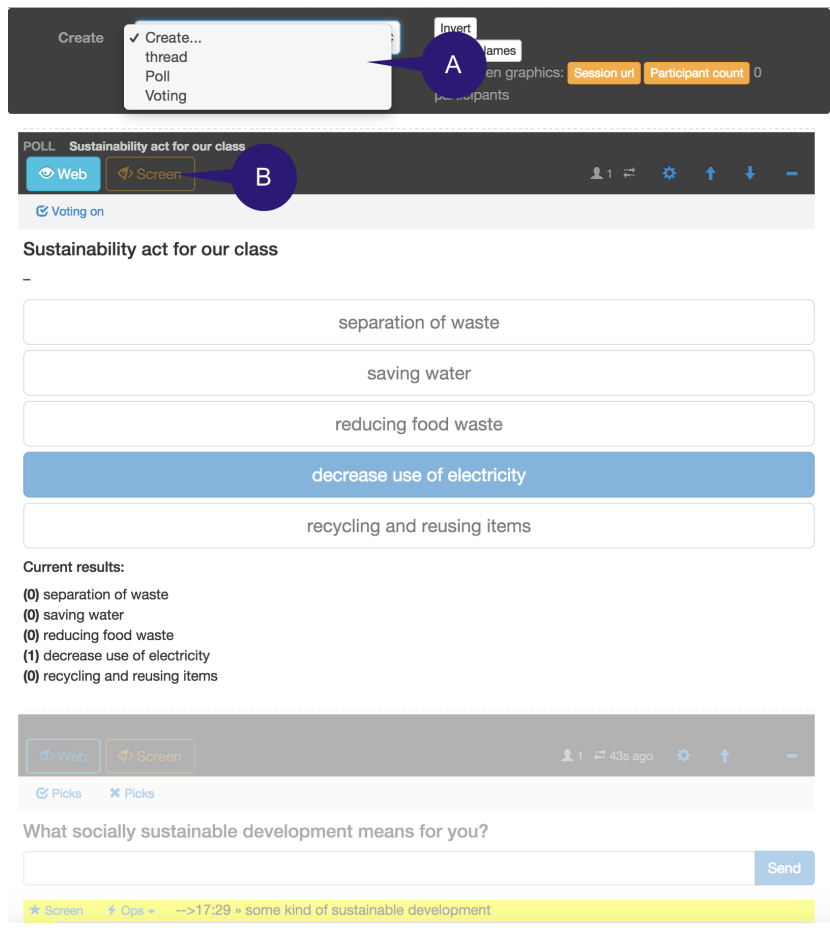

Fig. 2. Interface used to create (A) and manage (B) the interaction blocks

small-group education settings [17, 29], large-group education settings [19, 20], or professional settings [30].

Despite these apparent differences, the different settings share the same challenge: there are clear social roles between people [e.g. performers and audience; 46, 52] and the performers have the responsibility to ensure that the group work leads to suitable outcomes. If this challenge is overcome, even simple audience response systems, where the student is required to choose the right answer from a multiple-choice questionnaire, can improve learning results as they develop interactive and engaging learning situations [2, 10, 27, 34]. According to Nelimarkka et al. [46], beyond such a performer-centric use case (i.e., where the performer defines both the question and the alternative answers), dual-channel communication can also take the form of a mixed communication space [where the theme is set by the performer, but the answers are open ended, such as question management systems, 30] and purely audience-centric model [where the use of the digital channel is not controlled by the performer at all, like a backchannel, 43, 58, 71].

To engage with the questions of norms in dual-channel communication, we choose not to limit performers to only apply one performer-centric or audience-centric model but use them flexibly as needed. Presemo - the collocated synchronous communication system used in our study - allows for using several of these types of interactions, even at the same time [46].

Presemo allows the teacher to facilitate teaching via three different interaction blocks [46]. These are free-form or open-ended chats (Figure 1a), closed-ended polls (Figure 1b), and ranked content, which are mixtures of the two, whereby pupils are first prompted to answer an open-ended question, 
followed by a poll that ranks the options provided (Figure 1c). Presemo is an open source product, which made it possible for us to use it in this study. ${ }^{2}$

The system has three different user interfaces: a pupil interface that can be presented on devices with small screens (Figure 1); a public display that can be projected onto a big screen; and a control interface that allows the teacher to add (Figure 2, detail A) and manipulate the content. The content is stored on a server that these three clients are in continuous contact with.

Before Presemo can be used in a lesson, the teacher needs to create the required interaction blocks. This includes defining their titles. For closed-ended polls, it includes the answer options. In the classroom, the teacher can show and hide each block independently (Figure 2, detail B). Several blocks can also be shown to pupils simultaneously.

When a block is visible, pupils may enter answers using mobile devices such as phones or tablets. In the case of an open chat or ranked content, the teacher can also remove content sent by students. Finally, the teacher can finish the activity by hiding the blocks being used or by showing other blocks.

Presemo can be used in various ways in classroom teaching. For example, teachers may start a lesson with a closed-ended survey of pupils' viewpoints. This may be followed by a chat block underneath the survey. This allows for open-ended discussion and engages pupils in elaborating their answers. Another common strategy is to show a single interaction block to pupils for a limited amount of time. With its deceptively simple functionality, Presemo provides considerable versatility for teachers to introduce a digital channel to their teaching and to integrate it into classroom activities.

\subsection{Study setup}

We recruited two teachers from an elementary school in Helsinki, Finland, to a semester-long study. We informed the teachers that the study focused on mediated communication in a collocated situation and gave them a basic tutorial about Presemo. Both teachers taught 11-12-year-olds (i.e. fifth-year pupils in the Finnish school system).

Research in a school context with under-aged study participants involves ethical responsibilities. According to local guidelines from the Finnish National Board on Research Integrity, this study did not require an institutional ethical review. Instead, we were required to receive a written permission from guardians to participation in this study. From all participants, we received written permission for participation from both the pupils and their guardians. Finally, we ensured that all pupils (23 in both classes) were able to participate in this study, regardless of the technology available to them. First, we ensured that all pupils had a personal working smartphone to access Presemo and lent such devices to those pupils who did not own them. Second, the school had wireless network connectivity, which was used to connect to Presemo.

The study setup was open-ended: we gave teachers the freedom to choose how Presemo would be used in the classroom to support learning. A researcher was present about $10 \%$ of the time when Presemo was in use, and provided technical assistance when required. However, we avoided intervening in teaching during our visits, so as not to interfere with the practices of using Presemo.

The public screen was at the front of the classroom. Both teachers reconfigured the layouts of pupils' personal desks several times during the study, forming groups of four desks, pairs, individual desks, rows, and horse-shoe formations (see Figure 3).

Results concerning anonymity. We had initially considered that the research could use an experimental setting to explore anonymity and its impacts to norms given the prior literature suggesting it has a significant impact [among many others $35,51,53,55]$. In this research the results of anonymity

\footnotetext{
${ }^{2}$ See: http://github.com/presemo
} 


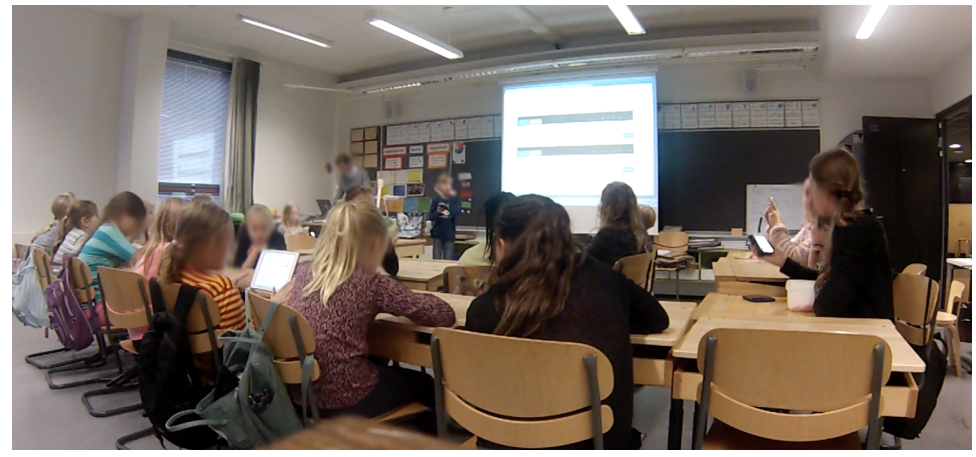

Fig. 3. Overview in one classroom of the study

and increased norm violations relate to social identity model of deindividuation effects [SIDE; e.g. 69]: people become deindividuated (i.e. lose a sense of individual identity and awareness) through anonymity. Previous research of dual-channel environments has shown that inappropriate or irrelevant content has amounted to as much as $20 \%$ to $45 \%$ of all content $[5,20,45]$. However, researchers have also suggested that there are positive impacts of anonymity in dual-channel cases. For example, audience members usually prefer anonymous participation because it allows for better self-expression and frees the members to present their subjective opinions without needing to consider how their peers will find them [45], are free to voice their ideas anonymously [48] and pay more attention to the content and not its senders, which thereby also increases its perceived value [16].

To understand anonymity better, we applied an A-B-A research design. In the first stage $\left(A_{1}\right)$, the two classes used Presemo for six weeks in a named mode in which the comments in open-ended chats were appended with pupils' names. In the second phase (B), also lasting six weeks, Presemo ran in an anonymised mode with the pupils' names hidden. The last phase $\left(A_{2}\right)$ was again in the named mode and lasted 2.5 weeks at the end of the semester. The A-B-A structure allowed us to explore changes caused by anonymity (Stage B) and control the learning effect (Stage $\mathrm{A}_{2}$ ). However, analysis showed no indicators of difference across the conditions (see Table $2 ; p=0.5, \chi^{2}=1.40$, $d f=2$ ). Therefore, we pooled the data together to examine norm violations more qualitatively.

\subsection{Data collection}

Our data collection focused on studying norm violations and how they were managed. The norm violations could be identified based on teachers' and pupils' behaviours and their personal accounts regarding the situation. We relied on three complementary methods to gather data: video recordings, interviews and $\log$ data analyses. This way we were able to triangulate the data from various sources. Furthermore, interviews and log data allowed us to examine cases that we did not observe directly.

Video recordings covered eight visits to a class (each was 45 minutes' long, the length of one class at this school). We used these visits to record overall behaviour in the classroom. Stages $A_{1}$ and $B$ contained three visits while Stage $A_{2}$ had two visits. We placed two cameras, equipped with wide-angle lenses, in the front corner and back corner of the classroom. The video data captured the auditory ambience in the classroom, the interactions between the teacher and the pupils, and many of the pupil-pupil interactions, including their physical movements. We explored the ways in which the teachers introduced Presemo for different educational tasks, and how they reacted to the content that the pupils posted to Presemo. 
In the interviews, we asked pupils and teachers to elaborate on their experiences at the end of each stage. Interviews with the teachers took 40-60 minutes. Interviews with the pupils took around five to ten minutes each and were done individually in a separate space. The time was short because pupils needed to engage in their ordinary schoolwork and thus could not be available for longer interviews. Because these interviews covered both classes, we carried out 63 individual interviews and three teacher interviews, the final one being a pair discussion with both teachers. Approximately eight hours of interview material was recorded.

Our interview scheme for the pupils focused on (i) their recall of activities they engaged within Presemo, and (ii) their own, (iii) their classmates', and (iv) their teachers' behaviours. ${ }^{3}$ We asked the teacher about their Presemo use, especially on those days when a researcher had not been present. We focused on hearing how and why they used Presemo and how the pupils took to using the system. We encouraged both the pupils and the teachers to elaborate on their answers. Furthermore, we asked the teachers for more details about observations we had made during our visits as well as those emerging from the pupils' interviews. We asked both the pupils and teachers high-level questions (see footnote 3 for examples) and invited them to elaborate their answers with examples whenever they could. These interviews also inquired about events that took place in those lessons where a researcher was not present. In particular, we asked pupils to describe a specific event they had in mind, or if they could not think of one, we suggested that they reflect on events informed by the system logs or teacher interviews.

We used the pupil interviews to inquire about events that we had recorded on video during the observation visits.

Log data from Presemo were available, consisting of contributions from the pupils and teachers with the system (e.g. all blocks created, all messages sent, all votes cast). We used the log data to gain insights into the digital activities: to quantify Presemo activity and to get an overview of it, as well as to classify pupils' messages based on their relevance to teachers' intended use.

\subsection{Analysis}

We studied how teachers and pupils reacted to activities in Presemo. The process followed open coding and the principles of iterative analysis [62]. We started by analysing the videos. We first sampled parts of the lessons for which Presemo was used and examined them further. We focused on phenomena that emerged because Presemo was present, under three themes: interaction between the teacher and Presemo, between the pupils and Presemo, and between the teacher and the pupils Codes from this analysis included, for example, teacher guidance on using Presemo (11 instances), the teacher reflecting on responses (one instance), laughter in the classroom triggered by Presemo (11 instances), and peer discussions about content in Presemo (16 instances).

We then conducted an iterative analysis of these codes (24 in total) and re-coded the data on more detailed levels, ensuring that the codes reflected the perspective of norms. We operationalized norm violations as events that "distracted the teacher or the pupil from teaching to attend to an unscheduled activity" [25]. According to earlier research, such norm violations may include off-task activities, such as off-topic messages in the digital channel [30,45], not being engaged in classroom activities [3], noisiness in the physical channel [3], pupils interacting with other pupils [3], and pupils interrupting the teacher [3]. We sought to use these categories to guide our analysis as the emphasis of our work was to understand how norm violations occur in a dual-channel communication environment, not what kind of norm violations exist. Therefore, grounding our

\footnotetext{
${ }^{3}$ Example questions included "What did you do with the participation channel" (the term we used to describe Presemo to teachers and pupils), "What did [teacher's name] do while you've used the participation channels", "What did it feel like to use the participation channel?" and "Were there any changes since the last time I did my interviews, which was just before the short holiday?"
} 


\begin{tabular}{lrrrrrr} 
& \multicolumn{3}{c}{ Class 1} & \multicolumn{3}{c}{ Class 2} \\
& $\mathrm{~A}_{1}$ & $\mathrm{~B}$ & $\mathrm{~A}_{2}$ & $\mathrm{~A}_{1}$ & $\mathrm{~B}$ & $\mathrm{~A}_{2}$ \\
\hline Days Presemo was used & 11 & 12 & 4 & 24 & 11 & 9 \\
$\quad$ Number of pupils & 23 & 23 & 23 & 23 & 23 & 23 \\
Teacher's use & & & & & & \\
Chat blocks created & 19 & 20 & 4 & 53 & 47 & 13 \\
Poll blocks created & 6 & 5 & 0 & 26 & 25 & 10 \\
Ranking blocks created & 7 & 2 & 0 & 1 & 2 & 0 \\
$\quad$ Total blocks per day & 2.9 & 2.3 & 1.0 & 3.3 & 6.7 & 2.6 \\
Pupils' use & & & & & & \\
$\quad$ Msgs / chat block & 40.3 & 42.3 & 39.8 & 43.4 & 29.9 & 34.1 \\
$\quad$ Votes / chat block & 10.8 & 6.8 & 0 & 14.5 & 14.2 & 13.8 \\
$\quad$ Msgs+votes / ranking block & 72.3 & 0 & 0 & 210 & 4 & 0 \\
\hline
\end{tabular}

Table 1. Descriptive statistics of Presemo use per stage, based on teachers' use (block creation) and pupils' use (content creation).

analysis with existing frameworks helped us to examine these events. However, our analysis focused also on cases where pupils' behaviours went against teachers' previous statements. When in doubt, we used other participants' reactions in our judgment as to whether a pupil-originated action represented a norm violation. After this, we examined how the teacher and the pupils managed these norm violations. Because of our interest in dual-channel interaction, we analysed only those times when Presemo was used.

We also used interviews to extend our observations and learn about Presemo use during those times when our researcher was not present in the classroom. Finally, we utilised interview data to triangulate our video-based inferences. Although it has been suggested that observed study participants would be present at video analysis sessions [33], this was not possible in our case, because of the large number of participants. When the interviews contradicted our initial video analysis, we revisited the videos and other interviews and corrected our interpretation.

\subsection{Contextualisation: How was Presemo used in the classroom?}

To understand our results, we consider that it is useful to provide some context how Presemo was used in the classrooms. Most importantly, Presemo was just one of many learning activities during the 45-minute classes. Teachers varied the types of activities during these lessons. In all cases that we observed, the teachers allocated dedicated time slots for Presemo use, articulating the aim of Presemo used. Usually, pupils sat in their places while the teacher, standing at the front of the room, showed the presentation view in the projector and gave the instructions (see Figure 3). We observed Presemo being used in religion, mother tongue, music, biology, environment and nature studies and history and civics classes, which correspond to subjects' teachers were teaching to the pupils. Presemo was used at all stages of the study (Table 1 and the A-B-A structure had only a moderate impact on the use of the technology. We normalised all conditions based on the number of blocks and tested whether student activity was higher in one of the stages using Wilcoxon's test. All tests were non-significant at $p \geq 0.1$, further supporting our choice to merge all stages of the study.

Presemo allowed different interaction forms, materialised through the blocks, to be used. Nelimarkka et al. [46] categorised the block use into eight different categories: collection of precise information, activation of the audience, engagement and co-creation with the audience, interaction with the performer, all-purpose chat (often with a title like "general discussion"), specific chat 
(where audience can drive the agenda), social lobby and event organisation. We conducted similar classification on all blocks to understand how teachers envisioned Presemo being used in the classroom. Dominantly, Presemo was used to collect precise information, that is, exploring statements that could be seen factually correct or incorrect. For example, in religion class, students were asked to write "Which symbol of the Holy Spirit is visible on the page [of the book]?" or answer a multiple-choice question "When the Priest raises his hands in the church, he wants to..." Such questions could be easily asked also in non-mediated environments. Teachers opted to use Presemo to assess the information of the whole class at the same time. During our classroom visits, we observed that teachers often adapted their later teaching activities based on the responses obtained through Presemo. For example, after a poll, erroneous answers were discussed and elaborated. Thus, the Presemo activity was threaded together with regular teaching activities and supplemented those, mostly through being scalable to the entire class. In many ways, this use case resembles emergently, without our request from teachers - many practices reported in audience response system research, such as those of choosing how to continue the performance or exploring how participants think about issues [10]. However, while audience response system researchers have often focused on multiple-choice questions, we observed that open answer fields (in a chat block) were predominantly used in the classes. This forced pupils to articulate their own answers to questions.

Different forms of activation and engagement were actively used. Instead of focusing on a factual statement, these sought to either introduce a theme by asking pupils to reflect a topic or support deeper engagement and personal reflection about a given topic. The Trojan horse was discussed in the class, with an open-ended chat "What have you heard about the Trojan horse?" This was followed by a deeper question, asking the pupils to reflect and connect the term to their daily experiences: "Have you been in a situation where something is different than it looks? C.f. Trojan horse" Also, Presemo was used to ask pupils to share their personal thoughts and experiences. For example, when discussing teenagers and puberty, the teacher asked students to answer the prompt "How do you know that your parents care about you?" We also observed that both teachers used Presemo to engage pupils in meta-cognitive tasks evaluating their own learning, following principles of active learning paradigms. Again, during interviews, teachers highlighted that they wished to engage pupils in different ways, and Presemo was one of the tools they used in there. Beyond the ability to engage all pupils to consider the theme and participate, teachers did not explicate why Presemo was used at specific times. Rather, it served as one additional modality of work in the classroom, connected with other classroom practices. As we have indicated through this summary on the use, both teachers were experienced and highly educated in the pedagogy. They used Presemo as one of many tools available for them to support in developing active and participatory learning experiences.

However, while it might appear that the Presemo use was an additional "gimmick" in the classroom, this was not the case. Rather, we observed pedagogically designed sequences that focused on the same theme over several blocks. For example, Finnish curriculum in mother tongue focused on the part of speeches. The teacher created several polls where students explored verbs: "Choose the right verb phrasing for the following sentence: Matt X blue berries in the forest." After several similar type of tasks, pupils were asked to answer an open-ended question "What is a verb?" This process followed the idea of a socio-constructivist learning paradigm, which is emphasised in the Finnish curriculum. Through answering several questions over several classes in Presemo as well as other class activities, pupils gained understanding and were able to answer the open-ended question. Similarly, we observed that even within one class, teachers followed similar sequences. For example, in the music class, pupils had just listened to a song and teacher asked "What grade would you give to this song?" followed by an open-ended discussion of "justify your grade." Based 


\begin{tabular}{|c|c|c|c|c|c|c|c|}
\hline \multirow[b]{2}{*}{ Violations type (onset $\rightarrow$ continuation) } & \multicolumn{2}{|c|}{ Stage $A_{1}$} & \multicolumn{2}{|c|}{ Stage B } & \multicolumn{2}{|c|}{ Stage $A_{2}$} & \multirow[b]{2}{*}{$\frac{*}{\stackrel{\pi}{0}}$} \\
\hline & $\frac{\vec{w}}{\tilde{z}}$ & $\begin{array}{l}\sim \\
\tilde{w} \\
\tilde{\Xi} \\
\tilde{U}\end{array}$ & $\begin{array}{l}\overrightarrow{0} \\
\text { త్ } \\
\vec{u}\end{array}$ & $\begin{array}{l}\sim \\
\tilde{w} \\
\frac{\tilde{U}}{u}\end{array}$ & $\frac{\vec{n}}{\tilde{\Xi}}$ & $\begin{array}{l}\sim \\
\tilde{w} \\
\tilde{\tilde{z}} \\
\tilde{U}\end{array}$ & \\
\hline \multicolumn{8}{|l|}{ Digital channel $\rightarrow$ digital channel } \\
\hline Non-relevant messages* & .54 & .64 & .36 & .59 & .32 & .45 & \\
\hline \multicolumn{8}{|l|}{ Physical channel $\rightarrow$ physical channel } \\
\hline Off-task activities & 0 & 4 & 0 & 0 & 0 & 0 & 4 \\
\hline \multicolumn{8}{|l|}{ Physical channel $\rightarrow$ digital channel } \\
\hline Non-relevant messages & 1 & 0 & 0 & 0 & 0 & 0 & 1 \\
\hline \multicolumn{8}{|l|}{ Digital channel $\rightarrow$ physical channel } \\
\hline General noise & 8 & 13 & 10 & 1 & 9 & 3 & 44 \\
\hline Pupils interrupting the teacher & 2 & 8 & 4 & 1 & 2 & 5 & 22 \\
\hline Pupils interacting with each other, ignoring teaching & 3 & 7 & 10 & 0 & 4 & 0 & 24 \\
\hline Pupils showing off and drawing attention & 1 & 1 & 0 & 0 & 0 & 0 & 2 \\
\hline Total $^{\star}$ & 15 & 33 & 24 & 2 & 15 & 8 & \\
\hline
\end{tabular}

* Reported as a percentage of non-relevant messages out of all messages in each stage, based on an analysis of a random sample of $10 \%$ of all messages.

$\star$ The total count does not include digital $\rightarrow$ digital violations as they are reported as percentages.

Table 2. Observed norm violations in the classrooms during Presemo use.

on teacher interviews, one motivation to use Presemo in these types of subjective questions was to engage all pupils within the class. Teachers observed that there are often a handful of active pupils, but through Presemo, even the quieter pupils could participate and be heard during the class.

\section{RQ1: HOW NORMS ARE VIOLATED}

We focused on analysing how norms are violations in dual-channel environment. First, we examined violations in both channels individually (see intended rows in Table 2). However, more extensive analysis illustrated that the cases of norm violations did not always occur on a single channel. Rather, they could also be sequences of channels onset in a channel but having their continuation on another channel (summarised later in Table 3). We indicate these using $\rightarrow$-symbol when discussing the empirical observations.

\subsection{Digital channel $\rightarrow$ digital channel violations}

The entirely digital norm violations were primarily related to sending non-relevant messages to Presemo during teaching. The violations emerged from a lack of appreciation for the purposes of the task given. These violations took pupils' attention away from teaching and broke the norm of staying focused and attentive. Most commonly these uses were related to spamming in Presemo's chat blocks. For example, in one case, a teacher received replies such as "Kfdkf" and "CHEEEEEEER" when he had asked pupils to post verbs that described their previous weekend. Another form of non-relevant messaging was related to using Presemo for insulting. Example messages of this type included "[pupil name] has poop in his pants" and "cheerleading is for teenyboppers." Such norm breaking can easily lead to further messages which break the norm [47].

\subsection{Physical channel $\rightarrow$ physical channel violations}

As pupils were allowed to use mobile devices in the classroom, they were responsible for using them to achieve the learning goals. Therefore, off-task activities constituted a form of norm violations. 
We observed four cases in our video data that were solely related to dual-channel interactions. In one case, a pupil played a game using his mobile device instead of participating via Presemo. This was a violation, as the pupil challenged the teacher's explicit guidance regarding the intended use of both Presemo and the mobile device. We classified this as 'physical $\rightarrow$ physical' because the behaviour did not relate to Presemo, which was the digital channel, but to the device that provided the communication channel instead. Playing a mobile phone game also created other sorts of unrest, such as sounds and other disruptions, in the classroom.

\subsection{Physical channel $\rightarrow$ digital channel violations}

Our data contained one case where the onset in the physical channel led to a digital continuation of the norm violation. Our classification of this case is based on the teacher's interpretation during an interview. The case involved several non-relevant messages that were sent during a history lesson that dealt with the domestication of animals in prehistoric times. The teacher had created a ranked content block in Presemo and asked the pupils for suggestions on the first animal species domesticated by humans. Pupils started to propose various purposely incorrect species. In the interview with us, Teacher 1 summarised that the pupils' norm-violation behaviour was caused by preceding events:

It became a dominant [pattern among pupils to compete over] who comes up with the funniest animal species, eel or seal or whatever. [- -] The participation channel is very context sensitive [- -]. The words I said [in the classroom] triggered this type of behaviour.

The teacher elaborated how the norm-violating behaviour in the physical channel spilled over into the digital sphere. Even when we were able to only demonstrate one such case in this study, we chose to designate a separate category for it, because many observations in prior work [6, 36] - without framing them as norm violations - have reported cases where physical activities have become onsets for norm violations in digitally mediated communications.

\subsection{Digital channel $\rightarrow$ physical channel violations}

Fourthly and lastly, the widest range of norm violations emerged when pupils reacted to digital actions within Presemo with physical actions in the classroom.

We will first describe how content in Presemo caused general noise, such as verbal remarks or laughter from the students. Presemo-related general noise manifested mostly when many pupils reacted to content in Presemo. For example, when off-task messages were posted, several pupils reacted by starting to laugh. Another form of general noise were the remarks that pupils made often by yelling - to comment on or to object to content in Presemo. The norm-violating nature of general noise was apparent in the teachers' reactions. Teacher 1 tried to establish a rule that using Presemo should not create any noise in the classroom. Thus, the various forms of general noise that the pupils made constituted clearly a norm violation in her case. We observed similar violations also in Class 2, however to a lesser extent, because Teacher 2 was more liberal about pupils' noise.

Pupils sometimes interrupted the teacher because they were so engaged in using Presemo. In our case we observed, for example, a pupil crying "No!" as she was just posting her comments, when the teacher said it is time to stop an activity in the digital channel. In another case, a pupil took over the role of the teacher, shouting responses, when the teacher started reviewing outcomes of a Presemo poll. The teacher responded to this firmly by stating that certain roles exist in class and that she is the teacher and he is the pupil. We find it possible that Presemo - as an environment that redistributes the agency to students - had a catalytic role in triggering this kind of violating behaviour. In the present case, the pupil had been given an active role in the lesson when he and others had a chance to contribute content to Presemo. When the teacher moved from the 

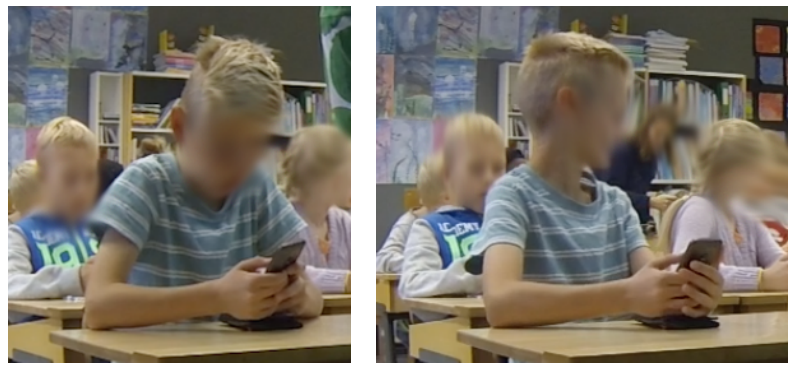

Fig. 4. Self-presentation by showing off: A pupil looking how others react to his norm-violating posting.

Presemo-focused activity to the next part of the lesson, the pupil remained in the active mode, suddenly creating a violation.

We also consider pupil-pupil interactions (e.g. talking) as norm violations if they interrupt the teaching or are against the rules that the teacher has set. In our data, such cases included pupils making remarks on the content and activities of other pupils in the physical channel. In Class 1 , where noisiness was strictly discouraged, pupils violated a norm whenever they talked with each other about Presemo content. Although the rules were more liberal in Class 2, discussions about the content were not always accepted, and shouting to other pupils across the room and walking over to other students were never treated as acceptable behaviour.

Finally, one norm violation types not clearly identified in the previous literature was selfpresentation. It happened when pupils attempted to draw attention to themselves, to show off, in front of their friends. In a typical pattern, pupils posted something to Presemo with a mobile device, after which they announced that content verbally to others. Then they waited for the others' reactions (see Figure 4). These acts of self-presentation were easy to carry out, because Presemo's content moderation was not turned on. .

\section{RQ2: PERFORMERS' STRATEGIES FOR MANAGING NORM VIOLATIONS}

While above we have recognized various kinds of norm violations, next we focus on how teachers tried to (re)establish the norms in Presemo, both proactively before and during Presemo use as well as reactively in response to norm violations.

\subsection{Proactive verbal norm management}

Proactive norm management strategies included actions by which the teachers could pre-empt norm violations that were otherwise in danger of occurring. Overall, these actions - often in the form of verbal instructions - were "soft" in the sense that they persuaded the pupils instead of explicitly directing them to behave in an intended way. Thus, to ensure smooth transitions between tasks with and without a digital channel, teachers usually explained the upcoming task and the reasons for using Presemo in it. This created an opportunity to align the pupils' norms of acceptable behaviour with their own. Teachers also explained what the desirable behaviours in Presemo during the task would be like:

[During a lesson, before pupils could comment in Presemo:]

Teacher 1: We have previously had some setbacks regarding the quality of these comments. We had a phase in which there was no spamming [- - in our school we use proper language and contribute politely [- $]$ 

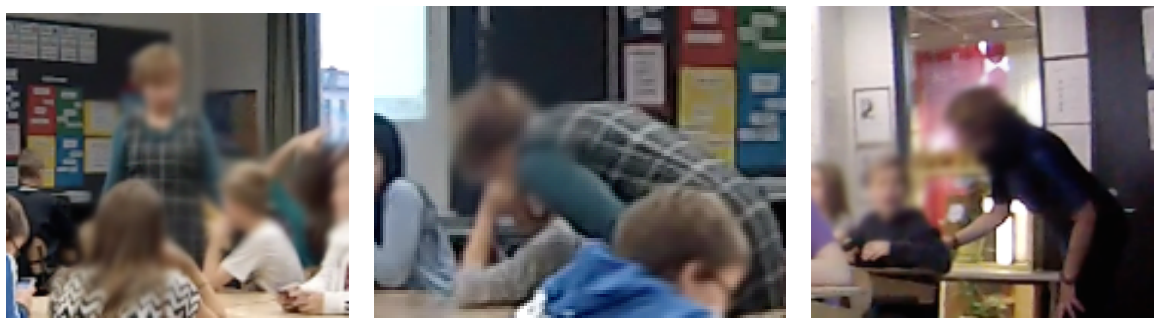

Fig. 5. Teachers reacting privately to pupils' norm-violating behaviours.

\subsection{Reactive overt verbal norm management}

In addition to proactive verbal guidance, teachers managed norms with reactive verbal remarks when Presemo was already in use. These took place in two forms: overtly (i.e. by addressing the whole class; discussed in this section) and privately (discussed in Section 5.3). With both types of remarks, the teachers cut short any actions in which violations had already happened (e.g. by telling that "[That kind of] insulting of others is not acceptable"). The overt remarks were rather general in tone and not aimed at a specific pupil (in comparison to the private remarks discussed below).

Pupils were aware of this management strategy, and adapted their behaviour to avoid such reactive norm management:

Pupil: [There are not negative comments] because [Teacher 1] keeps watch on the chat all the time, and if someone says there that your opinions suck and you've got it all wrong, [Teacher 1] makes a note of it.

\subsection{Reactive private norm management}

Both of the teachers engaged in private verbal remarks made directly to specific pupils in response to their behaviours. In one case, Teacher 1 walked to a pair of pupils and bent over to address them privately after their noisy behaviour (see Figure 5). Teacher 2, in a similar vein, mentioned that he had "private conversations on this topic" with one pupil who had played a mobile game during a lesson instead of using Presemo.

Interestingly, in both cases that we observed, the private remarks were simultaneously also overt. The content of the remark was kept private, either by using a low voice (Teacher 1) or by indirect remarks to what had been already communicated privately (Teacher 2 ). These acts were nonetheless also overt by being observable by anyone in the classroom. It seems that teachers deliberately wanted to signal to the whole classroom that they were managing a norm violation, even when the exact nature of the management remained private. Therefore, the visibility of one's physical actions could be used performatively in a publicly observable manner while at the same time verbal content of the intervention was kept private.

\subsection{Physical presence as norm management}

The power of physical presence became clear in one misunderstanding between thee teachers and pupils. Teacher 1's teaching style involved a lot of walking around the classroom during the lessons, including during Presemo-related tasks. The intention behind this behaviour was not readily apparent to the pupils. Similar to them, we also assumed that the teacher did this to monitor pupils and prevent violations, thus engaging in a proactive strategy:

Interviewer: Well, what has [Teacher 1] done [to address the bad content]? 
Pupil: [- -] sometimes she looks behind you in a way to sneak a glance at what you're writing: I feel that everyone focuses more on what they do when they notice that [Teacher $1]$ is behind them.

However, when we asked the teacher, she referred to this as "general control":

Interviewer: I've observed that you move around in the classroom.

Teacher 1: Yes, it might be. I don't mean to watch [pupils' phones]. I follow the public screen to check what's been said. So, it might be that I move around, but the goal has not been that I would see what the pupils write. Instead, it is more like general control.

Both interpretations point to a proactive norm management strategy, but in different ways. Teacher 1 wanted to prevent noise and other disturbances and to ensure that pupils would allow their classmates to post their opinions freely. The pupils, in turn, thought that the teacher wanted to exercise continuous control on what was being posted. Based on the pupils' comments, we can see that they were not able to distinguish general norm management from Presemo-specific norm management. We argue that what the teacher intended by her activity is not important; rather it is the pupils' constructed meanings that had an impact on their behaviour about the norms and their management. In this sense, physical presence can also be considered a proactive norm management strategy in the digital channel.

\section{DISCUSSION}

In this paper we explored social norms in dual-channel environments, where interaction took place both in physical and digital channels. To understand these norms, we focused to examine how norm violations take place (RQ1) and how do presenters address norm violations (RQ2). Our results suggest that in the design and analysis of collocated synchronous communication, care should be put to understand the digital and physical communication channels as a dual-channel environment, not as two separate channels. This idea is not limited by study's social context and age groups: while observed forms of norm violations may speak more about elementary schools and pupils, their existence across the dual-channels is not specific to how norms were broken [recall that norm violations have been observed in college and professional contexts as well, e.g. 5, 6, 20, 45].

Our work demonstrates the intertwined nature of norm violations in a dual-channel environment. Previously researchers have analytically separated physical and digital channels [39, 58]. We instead highlight they are interconnected when focusing closely on onsets and continuations. Our framework to account norm violations in a dual-channel environment (see Table 3) shows that the temporal dimension brings additional insights into the traditional physical and digital division. Using the framework, we identified cases where the onset of the violation took place in another channel than the continuation of the violation. Such norm violations spill over from one channel into another channel - a unique phenomenon for dual-channel communications. More critically, norm violations spillovers cannot be easily "encapsulated" to one channel only; instead they easily cross channel boundaries, escape the attention and control of the performer, and become harder to manage, as we have shown. Once a norm is violated in one channel, it can start to affect the other channel and cause further disruptions. We think that the framework can be expanded beyond norms and their violations to other social and behavioural factors in dual-channel environments.

To stress the importance of our work: spillovers were particularly harmful as performers mostly used a single channel for coping with norm violations (RQ2). Teachers' repertoire included public and private verbal remarks as well as physical presence, but it did not take place in the digital channel This repertoire demonstrated both proactive and reactive strategies were used, which was similar to what happens in more traditional, non-augmented classroom teaching. While Presemo allowed various interventions from performers, like writing comments or removing content, teachers

Proc. ACM Hum.-Comput. Interact., Vol. 5, No. GROUP, Article 221. Publication date: July 2021. 


\begin{tabular}{|c|c|c|c|}
\hline & & \multicolumn{2}{|c|}{ Onset in } \\
\hline & & Digital channel & Physical channel \\
\hline \multirow[t]{2}{*}{ Continuation in } & $\begin{array}{l}\text { Digital } \\
\text { channel }\end{array}$ & $\begin{array}{l}\text { A spectator posts non-relevant } \\
\text { content that encourages others } \\
\text { to do the same [30]. }\end{array}$ & $\begin{array}{l}\text { Pupils are restless and } \\
\text { contribute with off-task } \\
\text { content (Section 4.4). } \star\end{array}$ \\
\hline & $\begin{array}{l}\text { Physical } \\
\text { channel }\end{array}$ & $\begin{array}{l}\text { Pupils react to Presemo content } \\
\text { by laughing (Section 4.3). }\end{array}$ & $\begin{array}{l}\text { Pupils talk during class and } \\
\text { distract others [3]. }\end{array}$ \\
\hline
\end{tabular}

Table 3. Examples of norm violations types in dual-channel communication environment. $\star$ indicates novel spillovers identified in this study.

did not use them. Several factors can explain this observation. For example, cognitive load is a challenge for addressing both digital and physical channels [43]. However, the load was not always an impediment, because we did observe teachers being able to actively engage with digital content, such as asking follow-up questions verbally in the physical channel. Another reason might be that the digital interface was not suitable for teachers' use. Future research could examine whether shifting the focus from the classroom to a screen feels unnatural to teachers.

We will now move to further discuss two concepts which emerge from the framework demonstrated: spillovers and asymmetries. We first further define and contextualise them in the literature, and then show they can provide value for design of dual-channel environments.

\subsection{Spillovers and asymmetries as strong concepts for collocated synchronous communication}

To explicate the value of our research beyond elementary school context, we formulate main observations of the empirical work as strong concepts. Following Höök and Löwgren [32], we follow two stage process of the work: we discuss the observed phenomena relates to existing domain-specific research (horizontal grounding) and following that, demonstrate how other related domains have discussed similar phenomena as well (vertical grounding). This way, we demonstrate that the concepts do exists outside the context of our classroom studies and can help the research and design of collocated asynchronous communication tools in the future.

Our first candidate for strong concept is spillovers. We showed that some norm violations that started and continued in different channels. Norm violations can spillover both directions, from a digital channel to physical channel and from a physical channel to digital channel. The exact type of norm violation in question could change; for example, off-task content in Presemo, a challenging norm on proper behaviour in the classroom, could have been followed by pupil-pupil interaction, challenging the expectation of working alone in the task. Rather, the spillovers allowed cascading different types of norm violations in the classroom. From a practical perspective, spillovers require extra management from the performer to restored norms in both channels.

As articulated above, scholars have sought to understand interactions across communication channels in dual-channel research. Nelimarkka et al. [46] show that performers interact with their audience both through opening interaction blocks and using gaze, which is visible in the physical space. Similarly, Rodríguez-Triana et al. [58] show that the audience and performers interact both through face-to-face and computer-mediated channels. However, here the analysis is on a rather explicit interaction between the audience and performers. Lee and Tatar [39] add an additional dimension on this work: the cognitive space. They stay that a collaborative problemsolving task created a triple-space, not only digital and physical spaces, but a shared cognitive space as well. Spillovers address the same topic, but instead focus on complex group processes, like norm 
violations. The spillover is therefore less explicit than specific sequences of interactions which mix both channels, used often by the performers [46, 58] and not tied into analysis of collaboration [39]

In terms of vertical grounding, media and communication scholarship has discussed novel communication environments, where several channels are used, extensively. Hybrid media systems [11] draws attention to how new media adapts media logic of traditional media and vice versa Using our articulation, there are spillovers of media logic - such as media ethics and norms between traditional and new media. Hybrid media systems study media systems at a high level, but the adaptation - or spillover - has been seen as critical to understand the current media space. Similarly, channel complimentary theory [21] highlights how communication through a specific channel led to increased communication through other channels. Both works, dyadic and masspersonal communication show that the separation of action between communication channels is meaningless. Rather, the channels influence each other.

Our second proposal is asymmetry in the dual-channel environment. Our analysis showed that performers managed norms mostly in the physical channel, using both proactive and reactive strategies. Performers were not present in the digital channel, where most dual-channel norm violations originated in our study. This can in part explain some of the problems of norm management. When not present, using any coercive strategies - critical setting norms [38] - cannot be used in the channel. We observed that the audience was active in both channels. This finding indicates asymmetry of presence between the channels.

Other types of asymmetries could also be detected in dual-channel communication, such as asymmetry of power and asymmetry of focus. Previous work on collocated interaction highlights that systems may provide different interaction abilities [42] or different levels of information [49]. On a less abstract level, McCarthy and boyd [43] observe that following both channels is difficult because of the cognitive load, or asymmetry of attention: the audience may put more focus on the backchannel discussion while the performer focuses on the physical communication channel. Similarly, reflecting her experiences, boyd [6] was not aware about the digital channel and its content. The asymmetry of information led to a situation where she did not know why the audience was reacting through launching, making it difficult for her to deliver her presentation.

In terms of vertical grounding, the idea of asymmetries based on roles are well established, even in collocated systems $[42,49]$. Our focus on presence asymmetries however shifts the focus from interaction and information to actualised behaviour. For example, research on blended spaces-a mix of collocated and remote participants-have demonstrated issues related to awareness and control [4], rooting to issues related to presence. Similarly, the core problem in computer-mediated research has been that mediated channels afford less presence than face-to-face interaction [23] The observation that mediated presence is complicated is not novel. Through the idea of asymmetry of presence, we expand on this well-established literature to highlight that presence may be related to social roles as well and thus, contribute to asymmetries.

\subsection{Design implications}

This investigation was driven by a theoretical motivation: understanding norm violations in dualchannel communication. Through this investigation, we developed two conceptual innovations, spillovers and asymmetries, to help us articulate our findings. Following the idea of strong concepts [32], we now show that these concepts can provide insights for research practice in dual-channel communication. We will do so by showing how the design of dual-channel communication environments can benefit from these concepts.

First, we identified that there are spillovers that lead to norm violations in both channels. As this leads to additional effort to maintain (or negotiate) norms in two different channels, we considered spillovers harmful. We thus suggest ways to manage these spillovers in both a proactive and

Proc. ACM Hum.-Comput. Interact., Vol. 5, No. GROUP, Article 221. Publication date: July 2021. 
reactive manner. Reactive approaches could include "freezing the screen" from further contributions, shutting down the channel temporarily, and shutting down the public screen while also hiding other users' contributions from personal device screens. Such approaches mitigate the situation only after a spillover has taken place. They emphasise performers' norm management power and highlight that the norm management power is present also in the digital sphere, thus limiting the asymmetry of presence. It can also be used to cool down participation and allow participants to negotiate the norms of participation. However, they do not provide tools for more proactive management, which was the primarily manner teachers' managed norms.

We argue that designers and researchers of collocated synchronous communications systems should pay more attention to decrease this asymmetry because of the norm violation spillovers. A more balanced presence would increase performers' abilities to manage norms in both channels of dual-channel communication. Not only limiting the frequency of norm violation, the aim must be in limiting the spillovers that cause extended disruptions in the event. We offer two design implications for future research.

First, based on our observation that teachers sometimes successfully used proactive guidance to indicate how messages should be sent, we see opportunities in seeding the communication channels with desirable content. For example, in the interaction planning stage before the performance (e.g a lecture), the system could direct the performer to supply example answers, which then would be visible in the respective chat block. Seeded content would provide proactive guidance on the desired norms of the digital channel and supplement the performer's verbal guidance [65]. This way the expected behaviour rules would be more concretely exemplified, but more importantly, performers' presence in the digital space could be developed in a way that could be planned and executed before. This limits the cognitive load of this strategy and allows the performer to focus on the management of complex social settings.

Second, the asymmetry could be decreased by providing private feedback channels where the teacher could respond to pupils' actions. Using this, the teacher could be present in the digital channel without excessively intervening in communication that is visible to everyone. We acknowledge that provision of private norm-enforcing feedback may involve its own cognitive challenges, especially concerning split attention. As we observed, teachers already in this study managed to conduct such work - by walking to the pupils who seemed to cause disruptions. Similarly, they were able to verbally acknowledge content in-situ when pupils were still writing it. However, these require that they can give full attention to the participation and not for example, preparing the next activities, but instead focus on listening and facilitating the participation process. However, the above-mentioned activities only occurred in the physical space. It may be that writing textual comments would lead to cognitive overload. A suitable set of default features, ranging from soft methods such as emoticons to more coercive methods such as blocking, and nuanced feedback could be provided at a suitably low attentional cost. Positive and encouraging private feedback methods could also be offered to complement the solely negative and delimiting management features. The main aim of such intervention is to increase the presence of the teacher in the digital channel, but unlike the content seeding, this allows more reactive approaches in the norm management.

\subsection{Limitations}

Our decision to study a school setting may have prevented us from developing generalisable findings for some other contexts. For example, young people have less experience with computer-mediated communications in formal settings [40], and they require more guidance on the appreciation of shared social norms. Therefore, the norm management methods that we observed may not be appropriate in non-educational contexts. In addition, people of elementary school age are still developing their own identities [40], which means that their behaviours may not represent those of 
adults. Yet, the earlier literature showed that norm violations, such as posting antisocial messages and misusing digital channels have also been documented among adults and in non-educational contexts [e.g. 5, 6, 20,45]. Thus, we believe that dual-channel norm violations are a common and general phenomenon and that our findings provide additional insights into designing computermediated communication tools for other types of audiences.

We had to adapt our research methods to the school environment. We could conduct only short interviews with pupils, so as not to disrupt their schoolwork or create additional work for them in their own time. Longer interviews would have provided a deeper insight into the audience's experiences. The severity of this limitation can be best evaluated by conducting more studies in different settings. Similarly, analysis was unable to probe each member of the class in detail and thus, we might have missed more subtle norm violations. For example, we did not follow how pupilsâĂŹ attention changed during the use of the Presemo system, which might inhibit them from focusing on others' actions and responses.

Last, our video analysis and interviews did not capture discussions or behaviours related to norm negotiation. Rather, we focused on norms in a teacher-centric perspective, following the ideas of teaching as performance [52] and traditional analysis of these systems from the idea of performances [e.g. 46, 56]. The importance of norm negotiations depends on the social contexts where synchronous collocated communication is in use. In events where people are together only briefly, the room for shared norm negotiation is limited; such events are a common use context for these kinds of tools [46]. In these cases, there is a need to have a clear norm coherence as the collective norms are less developed. Furthermore, organisers and performers may need to ensure that code of conduct is followed. In our case study, the technology was in-use for a longer period. In these cases, norm violations may be needed to allow participants to negotiate about the norms. Thus, the design of mitigating norm violations must carefully consider that what agency does it provide to audience: in some cases, proposed performer-centric approaches could be transformed into peer-based mechanisms to support collective norm maintenance.

\section{CONCLUSIONS AND FUTURE WORK}

The social computing research community has not been actively focused on collocated and synchronous, or as we call them, dual-channel, collaborative environments [68]. However, commercial tools, such as Slido, Mentimeter, Poll Everywhere and Screen.io are already available to support such augmentation in collocated events. These commercial tools have provided easy ways for any performer or event organiser to augment a planned event with technology. There is therefore a growing need for research to help developers and practitioners to understand and improve systems and practices for dual-channel environments.

In response to this need, this paper examined norms in the dual-channel environment. Our analysis extended beyond the focus on either physical or digital channels and provided an integrated perspective on dual-channel environments. To achieve this, we focused to examine the temporal dimension of norm violations and demonstrated spillovers across and asymmetries between digital and physical channels. This indicates that norm violations and norm management require further analysis in dual-channel environments compared with single-channel environments.

Academics and practitioners may need to reflect on this communication environment in new ways. Although it may be tempting to think that performer-audience interactions in a collocated event could be easily augmented by providing participants with chat walls or "backchannels" these may as well disrupt the performance. Furthermore, a performance in the physical channel cannot be straightforwardly supported with a digital channel; the intended effect needs to be considered as an integrated phenomenon of dual-channel interaction instead of a simple augmentation of single-channel interaction. This paper has provided starting points for addressing the related

Proc. ACM Hum.-Comput. Interact., Vol. 5, No. GROUP, Article 221. Publication date: July 2021. 
challenges in such environments. Further work can continue to address other sociological concepts, like power, identity or awareness, and seek to examine how they are manifested in dual-channel environments.

\section{REFERENCES}

[1] Shannon Audley-Piotrowski, Alexandra Singer, and Mary Patterson. 2015. The role of the teacher in childrenâĂŹs peer relations: Making the invisible hand intentional. Translational Issues in Psychological Science 1, 2 (2015), 192.

[2] Ian D. Beatty, William J. Gerace, and Robert J. Dufresne. 2006. Designing Effective Questions for Classroom Response System Teaching. American fournal of Physics 74, 1 (2006), 31-39. https://doi.org/10.1119/1.2121753

[3] Grant Behnke, Eugene M. Labovitz, Janice Bennett, Cindy Chase, Jane Day, Charlotte Lazar, and David Mittleholtz. 1981. Coping with Classroom Distractions. The Elementary School fournal 81, 3 (1 1981), 135-155. https://doi.org/10. 1086/461217

[4] David Benyon and Oli Mival. 2015. Blended Spaces for Collaboration. Computer Supported Cooperative Work (CSCW) (2015), 223-249. https://doi.org/10.1007/s10606-015-9223-8

[5] Tony Bergstrom, Andrew Harris, and Karrie Karahalios. 2011. Encouraging Initiative in the Classroom with Anonymous Feedback. In Proceedings of the 13th IFIP TC 13 international conference on Human-computer interaction. 627-642. https://doi.org/10.1007/978-3-642-23774-4\{_\}49

[6] danah boyd. 2009. Spectacle at Web2.0 Expo. . from my perspective. Published online at http://www.zephoria.org/ thoughts/archives/2009/11/24/spectacle_at_we.html, accessed 2016-2-19..

[7] Ann L. Brown. 1992. Design Experiments: Theoretical and Methodological Challenges in Creating Complex Interventions in Classroom Settings. Journal of the Learning Sciences 2, 2 (4 1992), 141-178. https://doi.org/10.1207/ s15327809jls0202\{_\}2

[8] Barry Brown, Stuart Reeves, and Scott Sherwood. 2011. Into the Wild. In Proceedings of the 2011 annual conference on Human factors in computing systems - CHI '11. ACM Press, New York, New York, USA, 1657. https://doi.org/10.1145/ 1978942.1979185

[9] Rupert Brown. 1988. Group processes: Dynamics within and between groups. Basil Blackwell.

[10] Jane E. Caldwell. 2007. Clickers in the large classroom: Current research and best-practice tips. CBE Life Sciences Education 6, 1 (2007), 9-20. https://doi.org/10.1187/cbe.06-12-0205

[11] Andrew Chadwick. 2013. The Hybrid Media System: Politics and Power. Oxford University Press. https://doi.org/10. 1093/acprof:oso/9780199759477.001.0001\{T1\textbackslash\}r10.1093/acprof:oso/9780199759477.003.0001

[12] Lei Chang. 2004. The Role of Classroom Norms in Contextualizing the Relations of Children's Social Behaviors to Peer Acceptance. Developmental Psychology 40, 5 (2004), 691-702. https://doi.org/10.1037/0012-1649.40.5.691

[13] Arik Cheshin, Yongsuk Kim, D. Bos Nathan, Nan Ning, and Judith S. Olson. 2013. Emergence of Differing Electronic Communication Norms Within Partially Distributed Teams. Journal of Personnel Psychology 12, 1 (1 2013), 7-21. https://doi.org/10.1027/1866-5888/a000076

[14] P. Cobb, J. Confrey, A. diSessa, R. Lehrer, and L. Schauble. 2003. Design Experiments in Educational Research. Educational Researcher 32, 1 (2003), 9-13. https://doi.org/10.3102/0013189X032001009

[15] Allan Collins. 1992. Toward a Design Science of Education. In New Directions in Educational Technology. Springer Berlin Heidelberg, Berlin, Heidelberg, 15-22. https://doi.org/10.1007/978-3-642-77750-9\{_\}2

[16] Sarah M Davis. 2007. Impact of anonymity of input in next-generation classroom networks. In Proceedings of the 8th iternational conference on Computer supported collaborative learning. Association for Computational Linguistics, Morristown, NJ, USA, 165-167. https://doi.org/10.3115/1599600.1599631

[17] Margaret Dickey-Kurdziolek, Matthew Schaefer, Deborah Tatar, and Ian P Renga. 2010. Lessons from thoughtswap-ing. In Proceedings of the 2010 ACM conference on Computer supported cooperative work. ACM Press, New York, New York, USA, 81. https://doi.org/10.1145/1718918.1718934

[18] Helen M Doerr and Roxana Zangor. 1999. The teacher, the task and the tool: The emergence of classroom norms. International fournal of Computer Algebra in Mathematics Education 6, 4 (1999), 267-279. http://proxying.lib.ncsu.edu/index. php?url=http://search.ebscohost.com/login.aspx?direct=true\&db=eric\&AN=EJ647979\&site=ehost-live \&scope=site

[19] Honglu Du, Mary Beth Rosson, and John M. Carroll. 2012. Augmenting classroom participation through public digital backchannels. In Proceedings of the 17th ACM international conference on Supporting group work. ACM Press, New York, New York, USA, 155. https://doi.org/10.1145/2389176.2389201

[20] Honglu Du, Mary Beth Rosson, John M. Carroll, and Craig Ganoe. 2009. I felt like a contributing member of the class. In Proceedings of the ACM 2009 international conference on Supporting group work - GROUP '09. ACM Press, New York, New York, USA, 233. https://doi.org/10.1145/1531674.1531709

[21] Mohan J. Dutta-Bergman. 2004. Interpersonal communication after $9 / 11$ via telephone and internet: A theory of channel complementarity. New Media and Society 6, 5 (2004), 659-673. https://doi.org/10.1177/146144804047086 
[22] Paul R Ehrlich and Simon A Levin. 2005. The Evolution of Norms. PLoS Biology 3, 6 (6 2005), e194. https://doi.org/10. 1371/journal.pbio.0030194

[23] Clarence A. Ellis, Simon J. Gibbs, and Gail Rein. 1991. Groupware: some issues and experiences. Commun. ACM 34, 1 (1 1991), 39-58. https://doi.org/10.1145/99977.99987

[24] Edmund T Emmer and Laura M Stough. 2001. Classroom management: A critical part of educational psychology, with implications for teacher education. Educational Psychologist 36, 2 (2001), 103-112.

[25] Gaalen Erickson, Kate Hawkhead, and Peter Moody. 1980. Dealing with Classroom Distractions. The Elementary School fournal 81, 1 (1980), 40. https://doi.org/10.1086/461205

[26] D. C. Feldman. 1984. The Development and Enforcement of Group Norms. Academy of Management Review 9, 1 (1 1984), 47-53. https://doi.org/10.5465/AMR.1984.4277934

[27] Carmen Fies and Jill Marshall. 2006. Classroom Response Systems: A Review of the Literature. Journal of Science Education and Technology 15, 1 (3 2006), 101-109. https://doi.org/10.1007/s10956-006-0360-1

[28] Harold Garfinkel. 1967. Studies in Ethnomethodology. Prentice Hall, Englewood Cliffs, NJ.

[29] Drew Harry, Eric Gordon, and Chris Schmandt. 2012. Setting the stage for interaction: A Tablet Application to Augment Group Discussion in a Seminar Class. In Proceedings of the ACM 2012 conference on Computer supported cooperative work. ACM Press, New York, New York, USA, 1071-1081. https://doi.org/10.1145/2145204.2145364

[30] Drew Harry, Joshua Green, and Judith Donath. 2009. backchan.nl. In Proceedings of the 27th international conference on Human factors in computing systems. ACM Press, New York, New York, USA, 1361-1370. https://doi.org/10.1145/ 1518701.1518907

[31] John Heritage. 1984. Garfinkel and Ethnomethodology. Polity Press, Cambridge, UK.

[32] Kristina Höök and Jonas Löwgren. 2012. Strong concepts. ACM Transactions on Computer-Human Interaction 19, 3 (2012), 1-18. https://doi.org/10.1145/2362364.2362371

[33] Brigitte Jordan and Austin Henderson. 1995. Interaction Analysis: Foundations and Practice. Fournal of the Learning Sciences 4, 1 (1 1995), 39-103. https://doi.org/10.1207/s15327809jls0401\{_\}2

[34] Robin H. Kay and Ann LeSage. 2009. Examining the benefits and challenges of using audience response systems: A review of the literature. Computers \& Education 53, 3 (11 2009), 819-827. http://dx.doi.org/10.1016/j.compedu.2009.05 001

[35] Peter G. Kilner and Christopher M. Hoadley. 2005. Anonymity options and professional participation in an online community of practice. In Proceedings of the 2005 conference on Computer support for collaborative learning learning 2005. Association for Computational Linguistics, Morristown, NJ, USA, 272-280. https://doi.org/10.3115/1149293.1149328

[36] Kai Kuikkaniemi. 2017. LAIX-Score. A Design Framework for Live Audience Interaction Management Systems. Ph.D. Dissertation. Aalto University.

[37] David M. Lane and Rober S. Atlas. 1996. The networked classroom. In The meeting of Computers and Psychology. http://ctl.sri.com/publications/displayPublication.jsp?ID=321

[38] Maria Knight Lapinski. 2005. An Explication of Social Norms. Communication Theory 15, 2 (5 2005), 127-147. https://doi.org/10.1093/ct/15.2.127

[39] Joon Suk Lee and Deborah Tatar. 2014. Sounds of silence: Exploring Contributions to Conversations, Non-Responses and the Impact of Mediating Technologies in Triple Space. In Proceedings of the 17th ACM conference on Computer supported cooperative work \& social computing. ACM Press, New York, New York, USA, 1561-1572. https://doi.org/10. $1145 / 2531602.2531655$

[40] Sonia Livingstone, Leslie Haddon, Anke Görzig, and Kjartan Ólafsson. 2010. Risks and safety on the internet: the perspective of European children: key findings from the EU Kids Online survey of 9-16 year olds and their parents in 25 countries. (2010).

[41] Ben Loh, Sue Marshall, Josh Radinsky, Jennifer Mundt, and Kim Alamar. 1999. Helping students build inquiry skills by establishing classroom norms: How teachers appropriate software affordances. In Proceedings of annual conference of the American educational researchers association.

[42] Sus Lundgren, Joel E. Fischer, Stuart Reeves, and Olof Torgersson. 2015. Designing Mobile Experiences for Collocated Interaction. In Proceedings of the 18th ACM Conference on Computer Supported Cooperative Work \& Social Computing CSCW'15. 496-507. https://doi.org/10.1145/2675133.2675171

[43] Joseph F. McCarthy and danah boyd. 2005. Digital backchannels in shared physical spaces. In CHI '05 extended abstracts on Human factors in computing systems. ACM Press, 1641. https://doi.org/10.1145/1056808.1056986

[44] C. McLaughlin and J. Vitak. 2012. Norm evolution and violation on Facebook. New Media \& Society 14, 2 (2012), 299-315. https://doi.org/10.1177/1461444811412712

[45] Matti Nelimarkka, Kai Kuikkaniemi, and Giulio Jacucci. 2014. A Field Trial of an Anonymous Backchannel Among Primary School Pupils. In Proceedings of the 18th International Conference on Supporting Group Work. ACM Press, New York, New York, USA, 238-242. https://doi.org/10.1145/2660398.2660399 
[46] Matti Nelimarkka, Kai Kuikkaniemi, Antti Salovaara, and Giulio Jacucci. 2016. Live Participation. In Proceedings of the 2016 ACM Conference on Designing Interactive Systems - DIS '16. ACM Press, New York, New York, USA, 509-520. https://doi.org/10.1145/2901790.2901862

[47] Matti Nelimarkka, Vilma Lehtinen, Antti Ukkonen, Kai Kuikkaniemi, and Giulio Jacucci. 2015. Threading and conversation in co-located chats. Computers in Human Behavior 53 (12 2015), 324-331. https://doi.org/10.1016/j.chb. 2015.07.011

[48] Jay F. Nunamaker, Robert O. Briggs, Daniel D. Mittleman, Douglas R. Vogel, and Balthazard A. Pierre. 1996. Lessons from a Dozen Years of Group Support Systems Research: A Discussion of Lab and Field Findings. fournal of Management Information Systems 13, 3 (12 1996), 163-207. https://doi.org/10.1080/07421222.1996.11518138

[49] Thomas Olsson and Pradthana Jarusriboonchai. 2018. Technologies for Enhancing Collocated Social Interaction: Review of Design Solutions and Approaches. Fournal of Computer Supported Cooperative Work CMC (2018). https: //doi.org/10.1007/s10606-019-09345-0

[50] Antti Oulasvirta. 2012. Rethinking Experimental Designs for Field Evaluations. IEEE Pervasive Computing 11, 4 (10 2012), 60-67. https://doi.org/10.1109/MPRV.2011.84

[51] Zizi Papacharissi. 2004. Democracy online: civility, politeness, and the democratic potential of online political discussion groups. New Media \& Society 6, 2 (4 2004), 259-283. https://doi.org/10.1177/1461444804041444

[52] Elyse Lamm Pineau. 1994. Teaching Is Performance: Reconceptualizing a Problematic Metaphor. American Educational Research fournal 31, 1 (1994), 3-25.

[53] Tom Postmes and Russell Spears. 1998. Deindividuation and antinormative behavior: A meta-analysis. Psychological Bulletin 123, 3 (1998), 238-259. https://doi.org/10.1037//0033-2909.123.3.238

[54] T Postmes, R Spears, and M Lea. 2000. The formation of group norms in computer-mediated communication. Human Communication Research 26, 3 (7 2000), 341-371. https://doi.org/10.1111/j.1468-2958.2000.tb00761.x

[55] Tom Postmes, Russell Spears, Khaled Sakhel, and Daphne de Groot. 2001. Social Influence in Computer-Mediated Communication: The Effects of Anonymity on Group Behavior. Personality and Social Psychology Bulletin 27, 10 (10 2001), 1243-1254. https://doi.org/10.1177/01461672012710001

[56] Stuart Reeves, Steve Benford, Claire O’Malley, and Mike Fraser. 2005. Designing the spectator experience. In Proceedings of the SIGCHI conference on Human factors in computing systems - CHI '05. ACM Press, New York, New York, USA, 741. https://doi.org/10.1145/1054972.1055074

[57] Jun Rekimoto, Yuji Ayatsuka, Hitoraka Uoi, and Toshifumi Arai. 1998. Adding another communication channel to reality. In CHI 98 conference summary on Human factors in computing systems - CHI '98. ACM Press, New York, New York, USA, 271-272. https://doi.org/10.1145/286498.286752

[58] MarÃna JesÃžs Rodríguez-Triana, Adrian Holzer, Luis P. Prieto, and Denis Gillet. 2016. Examining the Effects of Social Media in Co-located Classrooms: A Case Study Based on SpeakUp. In Proceedings of 11th European Conference on Technology Enhanced Learning, EC-TEL 2016, Vol. 9891. 247-262. https://doi.org/10.1007/978-3-319-45153-4\{_\}19

[59] Jeremy Roschelle, Yannis Dimitriadis, and Ulrich Hoppe. 2013. Classroom orchestration: Synthesis. Computers \& Education 69 (11 2013), 523-526. https://doi.org/10.1016/j.compedu.2013.04.010

[60] Jeremy Roschelle, WR Penuel, and Louis Abrahamson. 2004. The Networked Classroom. Educational Leadership 61, 5 (2004), 50-55. http://www.eric.ed.gov/ERICWebPortal/recordDetail?accno=EJ716723

[61] M. Sherif and C. W. Sherif. 1969. Social Psychology. Harper \& Row, New York.

[62] David Silverman. 2000. Doing Qualitative Research. A practical handbook. SAGE Publications, London.

[63] Mel Stanfill. 2015. The Interface as Discourse: The Production of Norms through Web Design. New Media \& Society 17 , 7 (8 2015), 1059-1074. https://doi.org/10.1177/1461444814520873

[64] Natalie Jomini Stroud, Joshua M. Scacco, Ashley Muddiman, and Alexander L. Curry. 2015. Changing Deliberative Norms on News Organizations' Facebook Sites. Journal of Computer-Mediated Communication 20, 2 (3 2015), 188-203. https://doi.org/10.1111/jcc4.12104

[65] Kil-Soo Suh, Seongwon Lee, Eung-Kyo Suh, Hoseong Lee, and Jaehoon Lee. 2018. Online Comment Moderation Policies for Deliberative Discussion-Seed Comments and Identifiability. Fournal of the Association for Information Systems 19, 3 (2018).

[66] Abhay Sukumaran, Stephanie Vezich, Melanie McHugh, and Clifford Nass. 2011. Normative influences on thoughtful online participation. In Proceedings of the 2011 annual conference on Human factors in computing systems. ACM Press, New York, New York, USA, 3401-3410. https://doi.org/10.1145/1978942.1979450

[67] S. Uski and A. Lampinen. 2016. Social norms and self-presentation on social network sites: Profile work in action. New Media \& Society 18, 3 (3 2016), 447-464. https://doi.org/10.1177/1461444814543164

[68] James R. Wallace, Saba Oji, and Craig Anslow. 2017. Technologies, Methods, and Values: Changes in Empirical Research at CSCW 1990-2015. Proceedings of the ACM on Human-Computer Interaction 1, CSCW (12 2017), 1-18. https://doi.org/10.1145/3134741 
[69] Joseph B Walther. 2011. Theories of Computer-Mediated Communication and Interpersonal Relations. The SAGE Handbook of Interpersonal Communication (2011), 443-479.

[70] Rosemary Webb and Graham Vulliamy. 1999. Changing times, changing demands: a comparative analysis of classroom practice in primary schools in England and Finland. Research Papers in Education 14, 3 (10 1999), 229-255. https: //doi.org/10.1080/0267152990140302

[71] Sarita Yardi. 2006. The role of the backchannel in collaborative learning environments. In Proceedings of the 7th international conference on Learning sciences. 852-858. http://dl.acm.org/citation.cfm?id=1150034.1150158

Received August 2020; revised November 2020; accepted December 2020 